\title{
A zinc oxide-coated nanoporous carbon adsorbent for lead removal from water: Optimization, equilibrium modeling, and kinetics studies
}

\author{
G. Zolfaghari · A. Esmaili-Sari • M. Anbia • \\ H. Younesi - M. B. Ghasemian
}

Received: 23 November 2011/Revised: 20 May 2012/Accepted: 2 October 2012/Published online: 18 December 2012

(c) CEERS, IAU 2012

\begin{abstract}
A zinc oxide-coated nanoporous carbon sorbent was prepared by acid modification and $\mathrm{ZnO}$ functionalization of mesoporous carbon. The synthesized materials, such as mesoporous carbon, oxidized mesoporous carbon and zinc oxide-coated nanoporous carbon, were characterized by nitrogen adsorption-desorption analysis, Fourier transform infrared spectra, scanning electron microscopy, and transmission electron microscopy. $\mathrm{ZnO}$ on oxidized mesoporous carbon gradually increased with increase in the number of cycles. Furthermore, the effects of agitation time, initial metal ions concentration, adsorbent dose, temperature and $\mathrm{pH}$ on the efficiency of $\mathrm{Pb}(\mathrm{II})$ ion removal were investigated as the controllable factors by Taguchi method. The value of correlation coefficients showed that the equilibrium data fitted well to the Langmuir isotherm. Among the adsorbents, zinc oxide-coated nanoporous carbon showed the largest adsorption capacity of $522.8 \mathrm{mg} / \mathrm{g}$ $(2.52 \mathrm{mmol} / \mathrm{g}$ ) which was almost close to that of the zinc oxide-coated $(2.38 \mathrm{mmol} / \mathrm{g})$, indicating the monolayer spreading of $\mathrm{ZnO}$ onto the oxidized mesoporous carbon. The results of the present study suggest that $\mathrm{ZnO}$-coated nanoporous carbon can be effectively used for $\mathrm{Pb}(\mathrm{II})$ adsorption from aqueous solution, whereas a part of acidic functional groups may be contributed to binding the $\mathrm{Pb}$ (II) for the oxidized mesoporous carbon and mesoporous carbon.
\end{abstract}

G. Zolfaghari · A. Esmaili-Sari · H. Younesi

Department of Environment, Faculty of Natural Resources and Marine Sciences, Tarbiat Modares University,

P.O. Box: 46414-356, Noor, Mazandaran, Iran

M. Anbia ( $\square) \cdot$ M. B. Ghasemian

Research Laboratory of Nanoporous Materials, Faculty

of Chemistry, Iran University of Science and Technology,

Farjam Street, Narmak, 16846 Tehran, Iran

e-mail: anbia@iust.ac.ir
Kinetic studies indicated that the overall adsorption process of $\mathrm{Pb}$ (II) followed the pseudo-second-order model. The $\mathrm{ZnO}$-coated nanoporous carbon was regenerated and found to be suitable of reuse of the adsorbent for successive adsorption-desorption cycles without considerable loss of adsorption capacity.

Keywords Functionalization - Isotherm - Taguchi · Adsorption · Optimum conditions

\section{Introduction}

In recent years, contamination of aquatic ecosystems (e.g. lakes, rivers, stream, lagoons, oceans, etc.) with heavy metals has been receiving increased worldwide attention (Wagner and Boman 2003; Zolfaghari et al. 2007). Under certain environmental conditions, heavy metals may accumulate to a toxic concentration and cause ecological damage (El-demerdash and Elegamy 1996). The importance of research on protection against heavy metal pollution is widely acknowledged because of the various effects (Xu et al. 2011). Severe exposure to lead has been associated with sterility, abortion, stillbirths and neo-natal deaths (Goel et al. 2005). In this context, the recovery of lead from water and wastewater has become a major topic of research in water treatment. Out of the wastewater treatment methods involving lead and other heavy metal ions, precipitation, coagulation-sedimentation, adsorption, reverse osmosis, and ion exchange, adsorption is considered quite attractive because of its ease of handling, its economy, and its effectiveness in treatment of a great variety of dissolved material (Agrawal et al. 2005; Vukojevic Medvidovic et al. 2006). Various adsorbents for the removal of heavy metal such as activated carbon 
(Seco et al. 1997), sawdust of spruce (Urik et al. 2009), carbon nanotube (Li et al. 2005) and Leca (Malakootian et al. 2009) have been explored. Current US EPA drinking water standard for lead is $0.05 \mathrm{mg} / \mathrm{L}$ (Agrawal et al. 2005). Therefore, there is a considerable need to treat industrial effluents containing toxic heavy metals prior to discharge to protect public health and the necessity to exploit new high efficient adsorbents is great.

In recent years, mesoporous molecular sieves such as MCM-n (Mobil Crystalline Materials) (Kresge et al. 1992) and SBA-n (Santa Barbara Amorphous) (Zhao et al. 1998a, 1998b; Taguchi and Schuth 2005; Shahbazi et al. 2011) have attracted more and more attention owing to their particular properties, such as high surface areas, regular frameworks and narrow pore size distributions (Anbia and Mohammadi 2008; Anbia and Moradi 2009; Heidari et al. 2009). Ordered mesoporous carbons, CMK-n (Carbon Mesostructured by Korea Advanced Institute of Science and Technology) have recently been synthesized using ordered mesoporous silica templates (Ryoo et al. 1999, 2001). Mesoporous carbon materials can be used as an effective adsorbent in industry (Anbia and Mohammadi 2009; Anbia et al. 2010). Due to its open pore structure and mesoporous properties, mesoporous carbon provides marked advantages over typical activated carbon in the adsorption and diffusion processes. However, the hydrophobic and inert nature of mesoporous carbons can be unfavorable for several applications. Surface modification and functionalization of porous carbon materials are crucial not only for the development and application of hybrid mesoporous materials but also to change the hydrophobicity and hydrophilicity characters of the surface of the materials to make them available as good adsorbents (Vinu et al. 2007). It was reported that modified mesoporous carbon can be used as an adsorbent for removal of lead pollution (Baniamerian et al. 2009).

In the present study, highly ordered mesoporous carbon molecular sieves designated as CMK-3 were synthesized using mesoporous SBA-15 and then modified by $\mathrm{HNO}_{3}$ treatment. Oxidized mesoporous carbon (OCMK-3) was functionalized by $\mathrm{Zn}\left(\mathrm{NO}_{3}\right)_{2} \cdot 4 \mathrm{H}_{2} \mathrm{O}$. This modified nanostructure, zinc oxide-coated OCMK-3 is called Zn-OCMK-3. The possibility of adsorbing $\mathrm{Pb}$ (II) from aqueous solution by Zn-OCMK-3 adsorbent was also investigated. The Taguchi robust design method was used to optimize for each controllable factor such as agitation time, initial concentration, adsorbent dose, temperature and $\mathrm{pH}$.

The Taguchi design is a methodology to reduce cost, decrease development time and improve process quality control namely, system design, parameter design, and tolerance design (Taguchi 1990). Taguchi is developed a formulation in which the ratio of controllable factors (signal factors) to uncontrollable factors (noise factors), based on variance is independent of target value and is consistent with Taguchi quality objective. From the quality point of view, there are three possible categories of the quality characteristics: (1) smaller is better; (2) nominal is better; (3) bigger is better (Atil and Unver 2000). The Taguchi method uses the signal-to-noise ratio $(S / N)$ to express the scatter around a target value. A high value of $S / N$ implies that the signal is much higher than the random effects of the noise factors. Furthermore, the equilibrium data obtained were fitted to the Langmuir and Freundlich isotherms. Satisfactory agreement between experimental data and the model-predicted values was expressed by the correlation coefficient $\left(R^{2}\right)$. The kinetics of batch adsorption was also analyzed using pseudo-first and pseudo-second-order reaction models. This research was done in Research Laboratory of Nanoporous Materials, Iran University of Science and Technology, from April 2010 to April 2011.

\section{Materials and methods}

\section{Preparation of adsorbents}

\section{Synthesis of SBA-15}

The reactants used for synthesis of SBA-15 were tetraethyl orthosilicate (TEOS, $98 \%$ ), deionized water, Pluronic ${ }^{\circledR}$ $\mathrm{P} 123\left(\mathrm{EO}_{20} \mathrm{PO}_{70} \mathrm{EO}_{20}\right)$ and phosphoric acid $\left(\mathrm{H}_{3} \mathrm{PO}_{4}, 85 \%\right)$ from Aldrich (UK). Rod-like SBA-15 was synthesized according to the literature method reported by Colilla et al. (2008). The molar composition of the initial solution was $\mathrm{SiO}_{2}: \mathrm{P} 123: \mathrm{H}_{3} \mathrm{PO}_{4}: \mathrm{H}_{2} \mathrm{O}=1: 0.017: 1.5: 208$. First, $\mathrm{P} 123$ was dissolved in water and $2 \mathrm{M} \mathrm{HCl}$ solution. Then, TEOS was added into above solution and the resulting mixture was stirred for $24 \mathrm{~h}$ at $25{ }^{\circ} \mathrm{C}$. The white milky suspension was transferred into an autoclave, and was preserved for $24 \mathrm{~h}$ at $100{ }^{\circ} \mathrm{C}$. The product was directly filtered off without washing, dried at room temperature and then calcined in air at $550{ }^{\circ} \mathrm{C}$ for $6 \mathrm{~h}$.

\section{Synthesis of CMK-3}

CMK-3 was prepared according to the synthesis procedure described by Jun et al. (2000). The materials were purchased from Merck, Germany. In a typical synthesis, $1 \mathrm{~g}$ of SBA-15 as a hard template was added to a solution obtained by dissolving $1.25 \mathrm{~g}$ of sucrose as a carbon source and $0.14 \mathrm{~g}$ of $\mathrm{H}_{2} \mathrm{SO}_{4}$ as a catalyst in $5 \mathrm{~g} \mathrm{H}_{2} \mathrm{O}$. The resultant mixture was dried in an oven at $100{ }^{\circ} \mathrm{C}$ and, subsequently, the oven temperature was increased to $160{ }^{\circ} \mathrm{C}$. After $6 \mathrm{~h}$, the SBA-15 containing the partially carbonizing organic masses was added in aqueous solution consisting $0.75 \mathrm{~g}$ of 


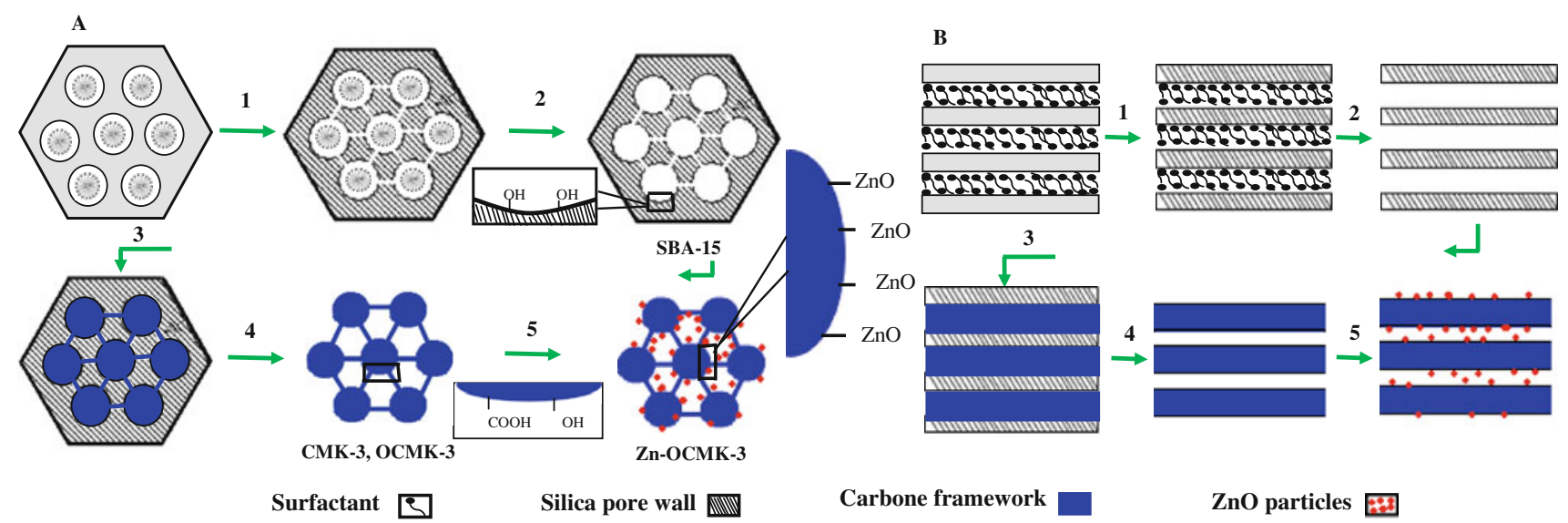

Fig. 1 Preparation strategy of zinc oxide-coated nanoporous carbon (a transverse section, b longitudinal section): 1 the silica introduction into the surfactant, 2 removal of the surfactant (P123) template, 3 the sucrose introduction into the channel of ordered mesoporous silica, 4 removal of the silica (CMK-3) and modification with $\mathrm{HNO}_{3}(\mathrm{OCMK}-$ 3 ), and 5 functionalization of zinc oxide on OCMK-3 (Zn-OCMK-3) sucrose, $0.08 \mathrm{~g}$ of $\mathrm{H}_{2} \mathrm{SO}_{4}$ and $5 \mathrm{~g}$ of water. The resultant mixture was dried again at $100{ }^{\circ} \mathrm{C}(6 \mathrm{~h})$ and $160{ }^{\circ} \mathrm{C}(6 \mathrm{~h})$. This powder sample was heated to $900{ }^{\circ} \mathrm{C}$ under vacuum. The carbon samples obtained after the silica removal were filtered, washed with ethanol and dried at $120{ }^{\circ} \mathrm{C}$.

\section{Acid modification of $C M K-3$}

The texture and surface chemistry of synthesized CMK-3 were modified by nitric acid under optimal oxidation condition, such as nitric acid concentration, and oxidation temperature (Bazula et al. 2008). First, $0.1 \mathrm{~g}$ of dried CMK-3 powder was treated with $15 \mathrm{ml}$ of $\mathrm{HNO}_{3}$ solution $(2 \mathrm{M})$ for $1 \mathrm{~h}$ at $80{ }^{\circ} \mathrm{C}$ under refluxing. After oxidation, samples were recovered and washed thoroughly with distilled water until the $\mathrm{pH}$ was close to 7 . Finally, carbon supports were filtered, washed with distilled water and dried at $108{ }^{\circ} \mathrm{C}$ for $12 \mathrm{~h}$. It was denoted as OCMK-3.

\section{Functionalization of OCMK-3}

Zinc nitrate tetrahydrate $\left(\mathrm{Zn}\left(\mathrm{NO}_{3}\right)_{2} \cdot 4 \mathrm{H}_{2} \mathrm{O}\right)$ was purchased from Merck, Germany for the functionalization process. The zinc oxide was coated to OCMK-3 by the equilibrium adsorption of $\mathrm{Zn}$ (II) ions from aqueous solution followed by calcination in air at $350{ }^{\circ} \mathrm{C}$ for $2 \mathrm{~h}$ to convert zinc nitrate to zinc oxide. The cycle was repeated four times to increase the amount of zinc oxide coating. The $\mathrm{Zn}$ (II) solution was prepared by dissolving $\mathrm{Zn}\left(\mathrm{NO}_{3}\right)_{2} \cdot 4 \mathrm{H}_{2} \mathrm{O}$ in THF $(1.5 \mathrm{~mol} / \mathrm{L})$. In order to reach the equilibrium state, $80 \mathrm{~mL}$ of $\mathrm{Zn}$ (II) solution including $2 \mathrm{~g}$ of the dried OCMK-3 was agitated at $150 \mathrm{rpm}$ for 3 days. After that, the solid was separated by filtration and then dried in oven at $110{ }^{\circ} \mathrm{C}$ before calcinations at $350{ }^{\circ} \mathrm{C}$. The zinc oxide-coated OCMK-3 was designated as Zn-OCMK-3.
The filtrate was analyzed by Inductively Coupled Plasma Atomic Emission Spectrometer (ICP-AES-Perkin-Elmer 4300 DV Model) to ensure complete adsorption. It was observed that the $\mathrm{Zn}$ was taken up by OCMK-3. Figure 1 shows preparation strategy of Zn-OCMK-3.

\section{Characterization of adsorbents}

Nitrogen adsorption-desorption isotherms of the synthesized samples were measured at $77 \mathrm{~K}$ on Micromeritics model ASAP 2010 sorptometer (Gregg and Sing 1982). Surface area of the sample was measured by BrunaureEmmet-Teller (BET) method (Emmett 1954). The Fourier transform infrared spectra (FT-IR) for the samples were measured on a DIGILAB FTS 7000 instrument under attenuated total reflection (ATR) mode using a diamond module (Stevenson 1994). Scanning electron microscopy (SEM) images were obtained with JEOL 6300F SEM. Transmission electron microscopy (TEM) images for determination of $\mathrm{ZnO}$ dispersion and morphology of samples were obtained using a $300 \mathrm{kV}$ Philips CM-30 TEM. Surface functional groups of CMK-3 and OCMK-3 were determined by the method of Boehm (2002). On the Boehm titration, the following assumptions were made to distinguish the surface carbon-oxygen complexes according to their acidity: $\mathrm{NaOC}_{2} \mathrm{H}_{5}$ neutralizes carboxylic, lactonic, phenolic, and carbonyl groups; $\mathrm{NaOH}$ neutralizes carboxylic, lactonic, and phenolic groups; $\mathrm{Na}_{2} \mathrm{CO}_{3}$ neutralizes carboxylic and lactonic groups; $\mathrm{NaHCO}_{3}$ only neutralizes carboxylic groups. One gram of the adsorbent was separately mixed with $15 \mathrm{~mL}$ of the above-mentioned basic solutions, and agitated at $100 \mathrm{rpm}$ for 4 days to complete the neutralization. Five milliliters of remaining basic solution was separated from the adsorbent, and back 
Table 1 Acidic surface functional groups of the adsorbents (Boehm titration)

\begin{tabular}{lll}
\hline Surface functional groups (meq./g) & CMK-3 & OCMK-3 \\
\hline Carboxylic groups & 0.15 & 3.00 \\
Lactonic groups & 0.13 & 0.13 \\
Phenolic groups & 1.60 & 1.60 \\
Carbonylic groups & 0.13 & 0.30 \\
\hline
\end{tabular}

titration was carried out by $0.1 \mathrm{M}$ hydrochloric acid using methyl red as a color change $\mathrm{pH}$ indicator (Table 1).

Adsorption measurements

\section{Optimization and prediction studies}

This study for determination of optimum conditions considers five controllable factors and each factor has four levels. Therefore, the experiments were designed as an L16 (45) orthogonal array, and the layout of which is given in Table 2. Note that only 16 experiments were selected, which were sufficient for our case. Stock solution of $1,000 \mathrm{mg} / \mathrm{L} \mathrm{Pb}(\mathrm{II})$ was prepared from $\mathrm{Pb}\left(\mathrm{NO}_{3}\right)_{2}$ as the lead source in deionized water containing a few drops of concentrated $\mathrm{HNO}_{3}$ to prevent hydrolysis. To study the adsorption process of $\mathrm{Pb}(\mathrm{II})$, batch sorption experiments were conducted. Adsorption tests were performed by shaking $500 \mathrm{~mL}$ amber Winchester bottles containing $100 \mathrm{~mL}$ of the $\mathrm{Pb}(\mathrm{II})$ in a Gallenkamp incubator shaker, stirring at $150 \mathrm{rpm}$. A series of aqueous solutions of $\mathrm{Pb}$ with the initial concentration of $10-400 \mathrm{mg} / \mathrm{L}$, temperature of $25-35{ }^{\circ} \mathrm{C}$, dose of $0.1-0.7 \mathrm{~g}, \mathrm{pH}$ of $2-7$ and agitation time of $10-240 \mathrm{~min}$ as Table 2 were prepared. The concentration of lead in the supernatant was analyzed with ICP-AES. The pollutant removal efficiency (PRE) is calculated using Eq. (1):

$\mathrm{PRE}=\frac{\left(C_{0}-C_{\mathrm{e}}\right)}{C_{0}} \times 100$,

where $C_{0}$ and $C_{\mathrm{e}}$ are the initial and the equilibrium concentrations of pollutant $(\mathrm{mg} / \mathrm{L})$, respectively. Because the target of this study is to maximize the PRE, the $S / N$ ratio with bigger is better characteristic is required, which is given by Eq. (2):

$\frac{S}{N}=-10 \log _{10}\left[\frac{1}{n} \sum\left(\frac{1}{\mathrm{PRE}_{i}}\right)^{2}\right]$.

In Eq. (4), $n$ is the number of rehearsal under the same experimental conditions.

The analysis of mean (ANOM) statistical approach is adopted herein to construct the optimal conditions. Initially, the mean of the $S / N$ ratio of each controllable factor at a certain level must be calculated. For example, $(M)_{\text {Factor }=I}^{\mathrm{Level}}$, the mean of the $S / N$ ratio of factor $I$ in level $i$, is given by

$(M)_{\mathrm{Factor}=I}^{\mathrm{Level}=i}=\frac{1}{n_{I i}} \sum_{j=1}^{n I i}\left[\left(\frac{\mathrm{S}}{\mathrm{N}}\right)_{\mathrm{Factor}=I}^{\mathrm{Level}=i}\right]_{j}$

where $n_{I i}$ represents the number of appearances of factor $I$ in the level $i$, and $\left[\left(\frac{S}{N}\right)_{\mathrm{Factor}=I}^{\mathrm{Level}=i}\right]_{j}$ is the $S / N$ ratio of factor $I$ in level $i$. By the same measure, the mean of the $S / N$ ratios of
Table 2 The $S / N$ ratio of each test

The boldfaces correspond to the maximum value of $S / N$ ratio among the 16 tests

$A$ agitation time (min),

$B$ concentration $(\mathrm{mg} / \mathrm{L}), C$ dose $(\mathrm{g} / \mathrm{L}), D$ temperature $\left({ }^{\circ} \mathrm{C}\right)$,

$E \mathrm{pH} . \mathrm{PRE}_{1}$ and $\mathrm{PRE}_{2}$ of $\mathrm{Pb}(\mathrm{II})$ represent the pollutant removal efficiency at first and second test pieces, respectively

\begin{tabular}{|c|c|c|c|c|c|c|c|c|c|}
\hline \multirow[t]{2}{*}{ Tests } & \multicolumn{5}{|c|}{ Factor } & \multicolumn{2}{|c|}{ PRE (\%) } & \multirow[t]{2}{*}{$S / N$} & \multirow[t]{2}{*}{ SD } \\
\hline & A & B & $\mathrm{C}$ & D & $\mathrm{E}$ & $\mathrm{PRE}_{1}$ & $\mathrm{PRE}_{2}$ & & \\
\hline Tests 1 & 10 & 10 & 0.1 & 20 & 2 & 28.00 & 28.30 & 28.98 & 0.21 \\
\hline Tests 2 & 10 & 100 & 0.3 & 25 & 4 & 31.00 & 28.74 & 29.48 & 1.59 \\
\hline Tests 3 & 10 & 200 & 0.5 & 30 & 6 & 63.00 & 63.01 & 35.98 & 0.007 \\
\hline Tests 4 & 10 & 400 & 0.7 & 35 & 7 & 48.40 & 46.50 & 33.51 & 1.34 \\
\hline Tests 5 & 30 & 10 & 0.3 & 30 & 7 & 65.50 & 65.35 & 36.31 & 0.10 \\
\hline Tests 6 & 30 & 100 & 0.1 & 35 & 6 & 55.50 & 55.45 & 34.88 & 0.03 \\
\hline Tests 7 & 30 & 200 & 0.7 & 20 & 4 & 32.50 & 32.49 & 30.23 & 0.007 \\
\hline Tests 8 & 30 & 400 & 0.5 & 25 & 2 & 26.60 & 26.00 & 28.39 & 0.42 \\
\hline Tests 9 & 120 & 10 & 0.5 & 35 & 4 & 78.50 & 78.35 & 37.88 & 0.10 \\
\hline Tests 10 & 120 & 100 & 0.7 & 30 & 2 & 68.50 & 66.30 & 36.56 & 1.55 \\
\hline Tests 11 & 120 & 200 & 0.1 & 25 & 7 & 51.00 & 51.10 & 34.15 & 0.07 \\
\hline Tests 12 & 120 & 400 & 0.3 & 20 & 6 & 41.00 & 41.10 & 32.26 & 0.07 \\
\hline Tests 13 & 240 & 10 & 0.7 & 25 & 6 & 95.75 & 95.75 & 39.62 & 0.00 \\
\hline Tests 14 & 240 & 100 & 0.5 & 20 & 7 & 68.00 & 68.98 & 36.71 & 0.69 \\
\hline Tests 15 & 240 & 200 & 0.3 & 35 & 2 & 48.50 & 48.00 & 33.66 & 0.35 \\
\hline Tests 16 & 240 & 400 & 0.1 & 30 & 4 & 32.70 & 32.60 & 30.27 & 0.07 \\
\hline
\end{tabular}


the other factors in a certain level can be determined. At the same way in Eq. (4), standard deviation (SD) of each factor was calculated.

$(\mathrm{SD})_{\mathrm{Factor}=I}^{\mathrm{Level}=i}=\left\{\frac{1}{n_{I i}} \sum_{j=1}^{n I i}\left[\left(\frac{S}{N}\right)_{\mathrm{Factor}=I}^{\mathrm{Level}=i}-(M)_{\mathrm{Factor}=I}^{\mathrm{Level}=i}\right]_{j}\right\}^{\frac{1}{2}}$.

Thereby, the $S / N$ response table and figure are obtained, and the optimal conditions are established. Finally, the confirmation experiments on solidification under these optimal conditions are carried out. Based on selection the five factors with the four levels, full factorial of this process has calculated as:

$N=L^{m}$

where $N$ is number of possible design, $L$ number of levels for each factor and $m$ is number of factors. For this study, $N$ is $1,024\left(4^{5}\right)$ tests. In contrast, in Taguchi method chooses only 16 tests. Other tests based on these $S / N$ ratios can be predicted as:

$\left(\frac{S}{N}\right)_{P}=\left(\frac{S}{N}\right)_{m}+\sum_{i=1}^{n}\left[\left(\frac{S}{N}\right)_{i}-\left(\frac{S}{N}\right)_{m}\right]$

where $(S / N)_{m}$ is the total mean $S / N$ ratio, $(S / N)_{i}$ is the mean $S / N$ ratio at the predicted level, and $n$ is the number of the main design parameters that affect the quality characteristic.

\section{Equilibrium modeling and kinetics studies}

For the investigation of equilibrium modeling and kinetics studies, a series of aqueous solutions of lead with the concentration of 10,100, 200 and $400 \mathrm{mg} / \mathrm{L}$ were performed. Exactly, $0.5 \mathrm{~g}$ of the mesoporous carbons, namely Zn-OCMK-3, OCMK-3, and CMK-3, was transferred carefully into the bottles and shaken vigorously for $120 \mathrm{~min}$ in an incubator shaker at temperature of $25^{\circ} \mathrm{C}$ and $\mathrm{pH}$ 6. The samples were filtered to remove and recover the adsorbent. The concentration of lead in the supernatant was analyzed with ICP-AES. The amount of lead adsorption at equilibrium, $q_{\mathrm{e}}(\mathrm{mg} / \mathrm{g})$ was calculated by Eq. (7):

$q_{\mathrm{e}}=\frac{\left(C_{0}-C_{\mathrm{e}}\right) V}{W}$,

where $C_{0}$ and $C_{\mathrm{e}}(\mathrm{mg} / \mathrm{g})$ are the initial and equilibrium liquid phase concentrations of $\mathrm{Pb}$ (II) ions, respectively, $V$ is the volume of the solution (L), and $W$ is the mass of dry adsorbent used (g) (Ayranci and Hoda 2005). The amount of adsorption at time $t$ was calculated by Eq. (8):

$q_{t}=\frac{\left(C_{0}-C_{t}\right) V}{W}$

where $C_{0}$ and $C_{t}(\mathrm{mg} / \mathrm{g})$ are the liquid phase concentration of $\mathrm{Pb}$ (II) ions at initial and time $t$, respectively. $V$ is the volume of the solution (L), and $W$ is the mass of dry adsorbent used (g) (Karagoz et al. 2008).

Regeneration studies

The reversibility of adsorption was investigated by carrying out regeneration experiments (Mangrulkar et al. 2008). The Zn-OCMK-3 was regenerated for three cycles to determine its reusability. To optimize acid concentration required for the quantitative stripping of the loaded lead, experiments were carried out by varying $\mathrm{HCl}$ concentrations $(0.10,0.15,0.20,0.25,0.30 \mathrm{M})$. Once equilibrium was reached, $\mathrm{Zn}$-OCMK-3 saturated with $\mathrm{Pb}$ (II) was removed from the solution and transferred into stoppered reagent bottles, containing $100 \mathrm{~mL}$ of $\mathrm{HCl}$ solution and the bottles were shaken at $150 \mathrm{rpm}$ for $2 \mathrm{~h}$ at room temperature $\left(25 \pm 1{ }^{\circ} \mathrm{C}\right)$ using a mechanical shaker. The sorbent was then removed by centrifugation. The concentrations of lead in the aqueous solutions were determined by ICP-AES. The lead recovery was calculated by the following equation:

$\mathrm{pb}(\mathrm{II})$ recovery $=\frac{\text { Amount of } \mathrm{pb}(\mathrm{II}) \text { desorbed }}{\text { Amount of } \mathrm{pb}(\mathrm{II}) \text { adsorbed }} \times 100$.

\section{Results and discussion}

\section{Properties of adsorbents}

Figure 2a shows that after modification with $\mathrm{HNO}_{3}$ and functionalization with $\mathrm{Zn}(\mathrm{II})$, the obtained carbons still have type IV isotherms, indicating that mesoporosity is still preserved and all of them are mesoporous materials (Kruk and Jaroniec 2001). The BET surface areas and pore volumes of CMK-3, OCMK-3 and Zn-OCMK-3 were calculated to be about 998,985 , and $1030 \mathrm{~m}^{2} / \mathrm{g}$ and 1.40 , 1.25 , and $1.10 \mathrm{~cm}^{3} / \mathrm{g}$, respectively. The most important property of an adsorbent is its adsorption capacity, which is related to its surface area. Generally, the higher the surface area, the larger is its adsorptive capacity (Noll et al. 1992). Furthermore, the pore size of CMK-3, OCMK-3 and Zn-OCMK-3 was calculated to be $4.3,3.9$, and $3.8 \mathrm{~nm}$, respectively. The FT-IR technique was used to monitor changes on the surface of the mesoporous carbon and the content of the introduced oxygen-containing functional surface group. Figure $2 \mathrm{~b}$ shows the FT-IR spectra of CMK-3 and OCMK-3 samples. Bands at 1,000-1,300 $\mathrm{cm}^{-1}$ $\left(1,103\right.$ and $\left.1,192 \mathrm{~cm}^{-1}\right)$ denoted the absorption of stretching vibration of $\mathrm{C}-\mathrm{O}$ bonds. The other peak at $1,713 \mathrm{~cm}^{-1}$ can be assigned to the stretching and bending vibration modes of $-\mathrm{COOH}$ on the surface of mesoporous carbon materials. The corresponding intensity of 1,103 , 1,192 and $1,713 \mathrm{~cm}^{-1}$ bands in OCMK-3 samples was higher than those of the CMK-3 sample, indicating that 

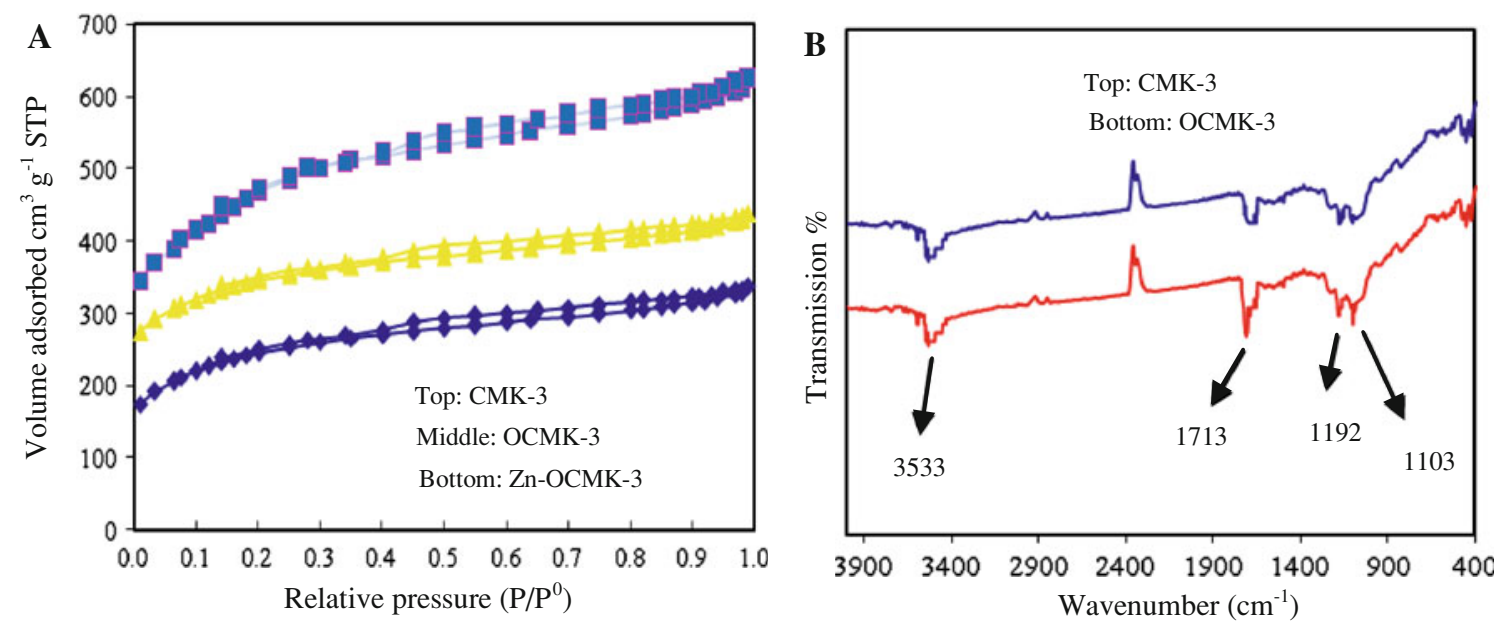

Fig. 2 a Adsorption-desorption isotherms of nitrogen on CMK-3, OCMK-3, and Zn-OCMK-3. b FT-IR spectra of CMK-3 and OCMK-3

more $\mathrm{C}-\mathrm{O}$ and $-\mathrm{COOH}$ functional groups were introduced during the oxidation. Furthermore, another band at around $3,533 \mathrm{~cm}^{-1}$ was observed in CMK-3 samples. It was mainly caused by the $\mathrm{O}-\mathrm{H}$ stretching vibration of the adsorbed water molecules (Chen et al. 2002; Vinke et al. 1994). The intensity of $3,533 \mathrm{~cm}^{-1}$ band in OCMK-3 was similar to that of CMK-3. Figure 3a reveals that the SBA15 sample consists of many rope-like domains, which are aggregated into wheat-like macrostructures. This image is in good agreement with the SBA-15 morphology presented in previous reports (Zhao et al. 1998a). Figure 3b shows the SEM image of CMK-3. The preservation of rope-like morphology during the SBA-15 template synthesis of CMK-3 from sucrose provides additional confirmation that carbon is faithful replica of the SBA- 15 . Furthermore, the carbon replica possesses the same wheat-like shape similar to the SBA-15. After oxidation treatments and functionalization with $\mathrm{ZnO}$, the morphology of CMK-3 is maintained as shown in Fig. 3c, d, respectively. The TEM for the carbon materials gave the regular pore image shown in Fig. 3e. The TEM image from thin edges of the carbon particles shows that the carbon molecular sieve has a uniform pore distribution, without carbon deposition on the external surface. Figure $3 \mathrm{f}$ clearly demonstrates the $\mathrm{ZnO}$ particulates deposited in the pores of the carbon. As it can be seen, $\mathrm{ZnO}$ is well dispersed on the carbon support.

\section{Amount of $\mathrm{ZnO}$ coating}

The amount of $\mathrm{ZnO}$ coating on OCMK-3 as a function of the number of zinc oxide coating cycles was studied (Fig. 4a). Zn(II) gradually increased with increase in the number of cycles with the equilibrium solution $\mathrm{pH}$ kept constant. As shown in Fig. $4 \mathrm{~b}$, the $\mathrm{Pb}$ (II) removal was proportionally promoted by introducing zinc oxide to the oxidized mesoporous carbon. No significant changes in equilibrium $\mathrm{pH}$ were observed for the $\mathrm{Pb}(\mathrm{II})$ adsorption on the $\mathrm{ZnO}$-coated OCMK-3 in each loading cycle.

\section{Optimization}

\section{Determination of optimum conditions}

The PRE in Tests 1-16 measured for $\mathrm{Pb}$ (II) according to the method and Eq. (1) (Table 2). Substituting the number of experimental repetitions and results of the measurement (PRE) into Eq. (2), the $S / N$ ratio of each test condition is determined (Table 2). $\mathrm{PRE}_{1}$ and $\mathrm{PRE}_{2}$ for $\mathrm{Pb}$ (II) represent the experimental results (the pollutant removal efficiency) at first and second test pieces, respectively. The boldface in Table 2 refers to the maximum value of $S / N$ ratio among the 16 tests. Test 13 has the higher $S / N$ (39.62) with the lowest SD $(<0.001)$. Subsequently, the values of the $S / N$ ratio were substituted into Eq. (3) and the mean of the $S / N$ ratios of a certain factor in the $i$ th level, $(M)_{\text {Factor }}^{\text {Level }}$, was obtained (Table 3). The $(M)_{\text {Factor }}^{\text {Level }}$ shows the effect of each level of each factor on the response, independently. It is calculated by averaging the $S / N$ ratio values of all the experiments, where the level of that factor has been used. For instance, one of the levels of factor B (concentration) is $10 \mathrm{mg} / \mathrm{L}$. According to Table 2, experiments corresponding to this level of concentration are tests $1,5,9$ and 13. Consequently, the $(M)_{\text {Factor }}^{\text {Level }}$ value of this level of concentration $(10 \mathrm{mg} / \mathrm{L})$ is equal to the average of the $S / N$ values obtained from those experiments. In Table 3, the boldfaces refer to the maximum value of the mean of the $S / N$ ratios of a certain factor among four levels, and thus it indicates the optimum conditions for adsorption process. From this Table, the optimum conditions for removal of $\mathrm{Pb}$ (II) are as follows: 

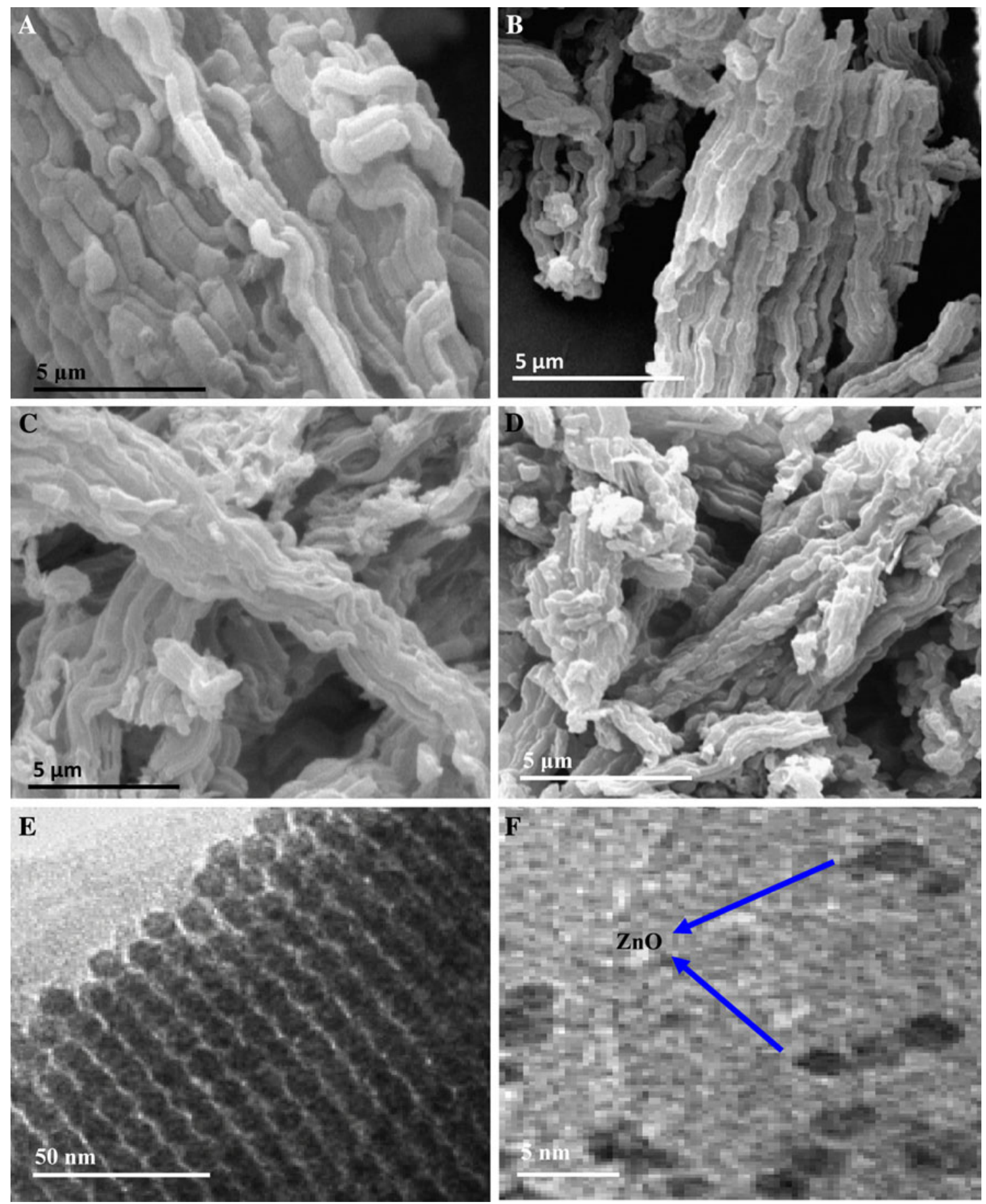

Fig. 3 SEM and TEM images of synthesized samples. a SEM image of rope-like morphology of SBA-15, b SEM image of CMK-3. c SEM image of OCMK-3, d SEM image of Zn-OCMK-3, e hexagonal structure of CMK-3 carbon, TEM, and $\mathbf{f}$ TEM image of Zn-OCMK-3

1. Agitation time of 120 min: To establish optimum time for maximum uptake, the adsorption of $\mathrm{Pb}(\mathrm{II})$ on Zn-OCMK-3 was studied as a function of agitation time and the results are shown in Fig. 5a. It is seen that the rate of uptake of the $\mathrm{Pb}$ (II) was rapid in the beginning and the time required for equilibrium adsorption was about $2 \mathrm{~h}$.
2. Initial concentration of $10 \mathrm{mg} / \mathrm{L}$ : Fig. $5 \mathrm{~b}$ shows that the $S / N$ decreases from 35.70 to 31.12 by increasing concentration from 10 to $400 \mathrm{mg} / \mathrm{L}$. Sufficient adsorption sites are available at lower initial concentration, but at higher concentration metal ions are greater than adsorption sites. Thus, it can be said that removal of lead is highly concentration dependent. Seco et al. (1997) 


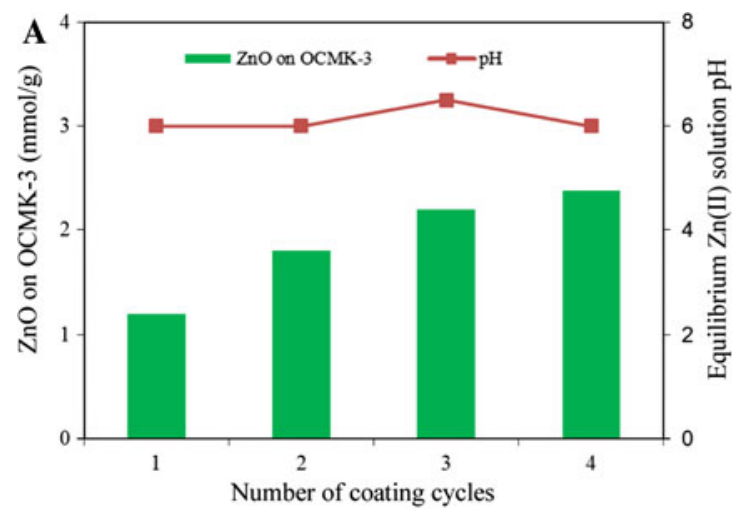

Fig. 4 a Amount of zinc oxide-coated to the OCMK-3 and equilibrium $\mathrm{pH}$ of $\mathrm{Zn}$ (II) solution. $\mathbf{b} \mathrm{Pb}$ (II) adsorption and equilibrium $\mathrm{Pb}$ (II) solution $\mathrm{pH}$ as afunction of the amount of zinc oxide-coated to the

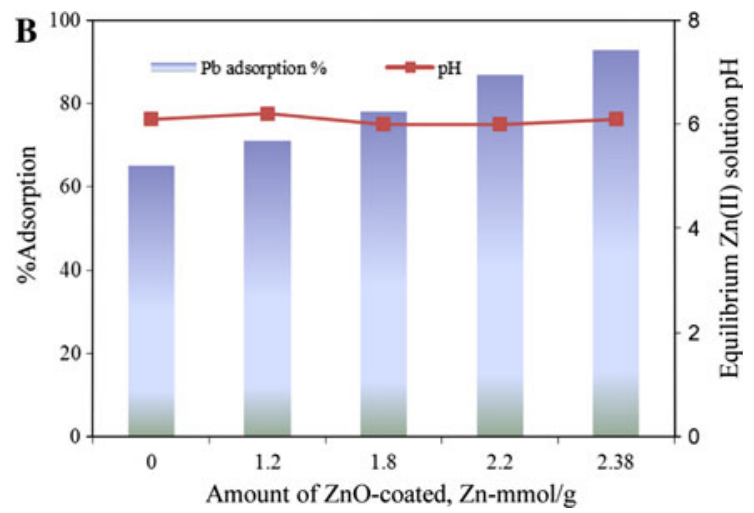

OCMK-3 (adsorbent dose $=0.5 \mathrm{~g} / \mathrm{L}$, agitation time $=120 \mathrm{~min}$, agitation speed $=150 \mathrm{rpm}$, room temperature $=25 \pm 1{ }^{\circ} \mathrm{C}$ )
Table $3 S / N$ ratio response table for $\mathrm{Pb}(\mathrm{II})$

\begin{tabular}{|c|c|c|c|c|c|}
\hline \multirow[t]{2}{*}{ Factor/level } & \multicolumn{4}{|c|}{$\left[\left(\frac{S}{N}\right)_{\text {Factor }}^{\text {Level }}\right]_{j}$} & \multirow[t]{2}{*}{$(M)_{\text {Factor }}^{\text {Level }}$} \\
\hline & $j=1$ & $j=2$ & $j=3$ & $j=4$ & \\
\hline $\mathrm{A} / 1$ & 28.98 & 29.48 & 35.98 & 33.51 & 32.00 \\
\hline $\mathrm{A} / 2$ & 36.31 & 34.88 & 30.23 & 28.39 & 32.46 \\
\hline $\mathrm{A} / 3$ & 37.88 & 36.56 & 34.15 & 32.26 & 35.22 \\
\hline $\mathrm{A} / 4$ & 39.62 & 36.71 & 33.66 & 30.27 & 35.07 \\
\hline $\mathrm{B} / 1$ & 28.98 & 36.31 & 37.88 & 39.62 & 35.70 \\
\hline$B / 2$ & 29.48 & 34.88 & 36.56 & 36.71 & 34.41 \\
\hline $\mathrm{B} / 3$ & 35.98 & 30.23 & 34.15 & 33.66 & 33.51 \\
\hline $\mathrm{B} / 4$ & 33.51 & 28.39 & 32.26 & 30.27 & 31.12 \\
\hline $\mathrm{C} / 1$ & 28.98 & 34.88 & 34.15 & 30.27 & 32.08 \\
\hline $\mathrm{C} / 2$ & 29.48 & 36.31 & 32.26 & 33.66 & 32.93 \\
\hline $\mathrm{C} / 3$ & 35.98 & 28.39 & 37.88 & 36.71 & 34.75 \\
\hline $\mathrm{C} / 4$ & 33.51 & 30.23 & 36.56 & 39.62 & 34.99 \\
\hline $\mathrm{D} / 1$ & 28.98 & 30.23 & 32.26 & 36.71 & 32.05 \\
\hline $\mathrm{D} / 2$ & 29.48 & 28.39 & 34.15 & 39.62 & 32.92 \\
\hline $\mathrm{D} / 3$ & 35.98 & 36.31 & 36.56 & 30.27 & 34.79 \\
\hline $\mathrm{D} / 4$ & 33.51 & 34.88 & 37.88 & 33.66 & 34.99 \\
\hline $\mathrm{E} / 1$ & 28.98 & 28.39 & 36.56 & 33.66 & 31.91 \\
\hline $\mathrm{E} / 2$ & 29.48 & 30.23 & 37.88 & 30.27 & 31.97 \\
\hline$E / 3$ & 35.98 & 34.88 & 32.26 & 39.62 & 35.69 \\
\hline $\mathrm{E} / 4$ & 33.51 & 36.31 & 34.15 & 36.71 & 35.18 \\
\hline
\end{tabular}

$0.7 \mathrm{~g} / \mathrm{L}$ dose of Zn-OCMK-3 $(S / N=39.75$ and removal percentage efficiency $=97.25 \%)$.

4. Temperature of $35^{\circ} \mathrm{C}$ : the uptake of $\mathrm{Pb}$ (II) onto the $\mathrm{Zn}-\mathrm{OCMK}-3$ increased with increase in temperature from 20 to $35^{\circ} \mathrm{C}$, indicating more chemical interaction between the sorbate and the surface functionalities of the Zn-OCMK-3 (Fig. 5d). Adsorption efficiency is observed to increase on raising the temperature, as previously reported (Marzal et al. 1996). 


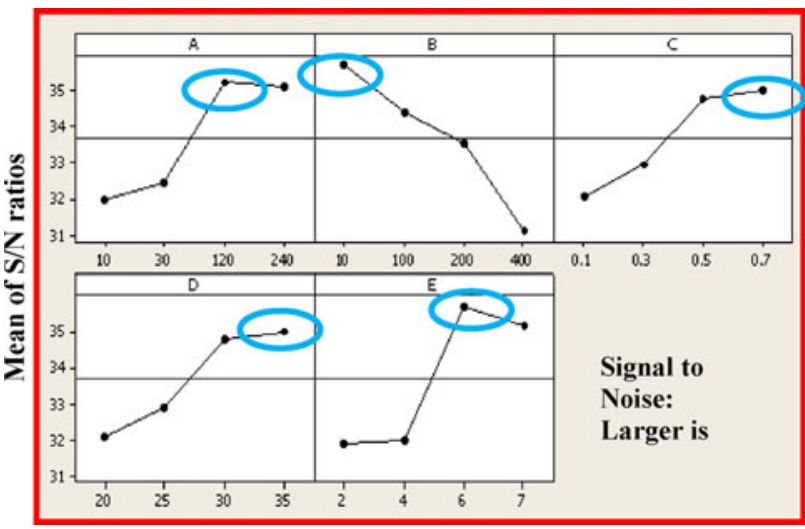

Fig. 5 a The effect of agitation time (min), b initial concentration $(\mathrm{mg} / \mathrm{L}), \mathbf{c}$ dose of adsorbent $(\mathrm{g} / \mathrm{L})$, $\mathbf{d}$ temperature $\left({ }^{\circ} \mathrm{C}\right)$, and e $\mathrm{pH}$ of solution, on the $S / N$ ratio in the removal of lead (II) by zinc oxidemodified mesoporous carbon CMK-3. Circles on figures indicate optimum conditions for adsorption process

5. $\mathrm{pH}$ of 6: the $\mathrm{pH}$ of aqueous medium is an important factor that may influence the uptake of the adsorbent. The chemical characteristics of both the adsorbent and the adsorbate vary with $\mathrm{pH}$. The $\mathrm{pH}$ of the solution affects the degree of ionization and speciation of various pollutants which subsequently leads to a change in reaction kinetics and equilibrium characteristics of the adsorption process. The effect of solution $\mathrm{pH}$ on adsorption of $\mathrm{Pb}(\mathrm{II})$ by $\mathrm{Zn}$-OCMK-3 was studied. In the alkaline range, the $\mathrm{pH}$ was varied using aqueous $\mathrm{NaOH}$, whereas in the acidic range, $\mathrm{pH}$ was varied using $\mathrm{HCl}$. The $S / N$ ratio for the uptake of the $\mathrm{Pb}$ (II) on the adsorbents is shown in Fig. 5e. The adsorption of the $\mathrm{Pb}$ (II) was reached maximum at $\mathrm{pH}$ 6 , and decreased at the $\mathrm{pH}$ values higher than 6 . At low $\mathrm{pH}(\mathrm{pH}=2)$, adsorption is very weak due to the competition of $\mathrm{H}_{3} \mathrm{O}^{+}$. This is confirmed by slight increase of $\mathrm{pH}$ (Eiden et al. 1980; Li et al. 2002; Han et al. 2006). Moreover, at higher $\mathrm{pH}$ increase of $\mathrm{pH}$ of the aqueous solution leads to the hydrolysis of $\mathrm{Pb}$ (II) species. The surface functional groups may exchange a proton with positively charged $\mathrm{Pb}$ (II) in aqueous solution forming ion exchanged complex (Wang et al. 2007). Furthermore, the point of zero charge $\left(\mathrm{pH}_{\mathrm{zpc}}\right)$ plays an important role in the adsorption process (Kikuchi et al. 2006). The point of zero charge $\left(\mathrm{pH}_{\mathrm{zpc}}\right)$ was obtained from Fig. 6 according to the method of Smiciklas et al., (2000). The equilibrium solution $\mathrm{pH}$ was plotted against the initial solution $\mathrm{pH}$ for $\mathrm{Zn}-\mathrm{OCMK}-3$; the constant equilibrium solution $\mathrm{pH}$ exhibiting the point of zero charge $\left(\mathrm{pH}_{\mathrm{zpc}}\right)$ was attained by increasing the initial $\mathrm{pH}$ as shown in Fig. 6. The $\mathrm{pH}_{\mathrm{zpc}}$ of $\mathrm{Zn}-\mathrm{OCMK}-3$ was found to be 4.8 . At $\mathrm{pH}$ above $\mathrm{pH}_{\mathrm{zpc}}$, the surface of mesoporous carbon

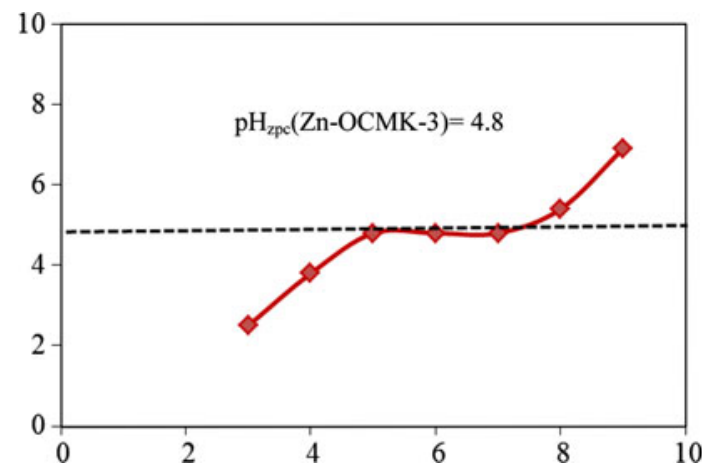

Fig. 6 Relationship of equilibrium solution $\mathrm{pH}$ and initial solution $\mathrm{pH}$ for the mixture of $0.1 \mathrm{M}$ potassium nitrate solution and $\mathrm{Zn}-\mathrm{OCMK}-3$

is negative and there is a strong electrostatic attraction between surface groups and $\mathrm{Pb}$ (II). As a result, above $\mathrm{pH}_{\mathrm{zpc}}$, the adsorption of $\mathrm{Pb}(\mathrm{II})$ was found to be high. At $\mathrm{pH}$ values less than $\mathrm{pH}_{\mathrm{zpc}}$, the carbon surface is positively charged resulting in lower adsorption due to electrostatic repulsion between the positive surface charge of mesoporous carbon and $\mathrm{Pb}$ (II).

The confirmation experiment was carried out according to the afore-mentioned optimum conditions, the PRE of $\mathrm{Pb}$ (II) registered, and the $S / N$ ratio was calculated. The value of the $S / N$ ratio under optimum conditions (39.75) slightly exceeds that in Test 13 (39.62), and the average PRE under optimum conditions $(97.25 \%)$ indeed exceeds that in Test $13(95.75 \%)$. Although the difference of the $S / N$ ratio between the optimum conditions and Test 13 is very little, the agitation time substantially decreases from $4 \mathrm{~h}$ (Test 13) to $2 \mathrm{~h}$ (optimum conditions). Furthermore, the PRE increases from 95.75 to $97.25 \%$ for $\mathrm{Pb}$ (II).

\section{Prediction}

As mentioned before, the full factorial of this study is 1,024 tests. The other test conditions were predicted by Eq. (6). For instance $(S / N)_{i}$ for Test 1 (A/1, B/1, C/1, D/1 and $\mathrm{E} / 1$ ) can be obtained from Table 2 and the values are 32.00 , $35.70,32.08,32.05$ and 31.91 , respectively. The value of $(S / N)_{m}$ calculated from Table 3 is 33.67. Using these values, Eq. (6) can be written as $(S / N)_{P}=33.67+[(32.00-$ $33.67)+(35.70-33.67)+(32.08-33.67)+(32.05-$ $33.67)+(31.91-33.67)]$. Therefore, the predicted $(S / N)_{\mathrm{P}}$ ratio (29.06) for removal of $\mathrm{Pb}$ (II) by $\mathrm{Zn-OCMK-3}$ can be obtained and the corresponding estimated adsorption can also be calculated using Eq. (2). In other words, the value of $(S / N)_{P}(29.06)$ is substituted into Eq. (2), and then Eq. (2) can be expressed as $29.06=-10 \cdot \log (1 / \mathrm{PRE})^{2}$. Finally, estimated adsorption $(28.41 \%)$ can be obtained that is near to 
Table 4 Comparing real amount of PRE with its prediction

\begin{tabular}{lllllllll}
\hline Time & Concentration & Dose & Temperature & $\mathrm{pH}$ & $(S / N)_{\text {predicted }}$ & $(\text { PRE })_{\text {predicted }}$ & $(\text { PRE })_{\text {real }}$ & Error $(\%)$ \\
\hline 10 & 100 & 0.1 & 25 & 4 & 28.62 & 26.91 & 26.00 & 3.38 \\
10 & 200 & 0.7 & 30 & 6 & 36.22 & 64.71 & 64.50 & 1.10 \\
10 & 400 & 0.1 & 35 & 7 & 30.60 & 33.88 & 33.00 & 2.59 \\
30 & 10 & 0.7 & 30 & 7 & 38.36 & 82.79 & 82.20 & 0.71 \\
240 & 10 & 0.7 & 20 & 6 & 38.75 & 88.59 & 88.50 \\
\hline
\end{tabular}

real amounts in Table 2 (28.00 and 28.30) with $0.91 \%$ error. For better validation of Eq. (6), some other conditions were carried out at Table 4. The overall experimental error was $1.75 \%$, indicating this estimation is acceptable.

Equilibrium modeling

\section{Adsorption isotherms}

In order to indicate the sorption behavior and to estimate of adsorption capacity, adsorption isotherms have been studied. The adsorption process of $\mathrm{Pb}(\mathrm{II})$ on $\mathrm{CMK}-3$, OCMK-3, and Zn-OCMK-3 nanoadsorbents was tested with Langmuir and Freundlich isotherms which correspond to homogeneous and heterogeneous adsorbent surfaces, respectively (Purna Chandra Rao et al. 2006). The Langmuir model is given by Eq. (10):

$q_{\mathrm{e}}=\frac{q_{\mathrm{m}} b C_{\mathrm{e}}}{1+b C_{\mathrm{e}}}$

where $C_{\mathrm{e}}$ is the equilibrium $\mathrm{Pb}(\mathrm{II})$ ion concentration $(\mathrm{mg} / \mathrm{L})$, $q_{\mathrm{e}}$ is the amount of $\mathrm{Pb}(\mathrm{II})$ adsorbed at equilibrium $(\mathrm{mg} / \mathrm{g})$, $q_{\mathrm{m}}(\mathrm{mg} / \mathrm{g})$ and $b(\mathrm{~L} / \mathrm{mg})$ are the Langmuir constants. In other words, $q_{\mathrm{m}}$ is the maximum adsorption capacity and $b$ is the adsorption affinity onto the adsorption sites and it is related to energy of adsorption (Morey et al. 2000). Also, the Freundlich model is given by Eq. (11):

$q_{\mathrm{e}}=k_{\mathrm{f}} C_{\mathrm{e}}^{\frac{1}{n}}$

where $C_{\mathrm{e}}$ is the equilibrium metal ion concentration $(\mathrm{mg} / \mathrm{L})$, $q_{\mathrm{e}}$ is the amount of $\mathrm{Pb}(\mathrm{II})$ removed $(\mathrm{mg} / \mathrm{g}), K_{\mathrm{f}}$ is the constant related to the adsorption capacity of the adsorbent, and $n$ is the empirical constant related to the intensity of adsorption which varies with the heterogeneity of the adsorbent (Ho et al. 2002). The greater the value of $n$, the more favorable is the adsorption process. Non-linear regression analysis was performed in SigmaPlot software (SigmaPlot 6.0 , SPSS Inc., USA) to estimate the values of $q_{\mathrm{m}}, b, K_{\mathrm{f}}$ and $n$ parameters. The non-lineared Langmuir and Freundlich adsorption isotherms of $\mathrm{Pb}$ (II) ions obtained at the adsorbent dose of $0.5 \mathrm{~g} / \mathrm{L}$ and temperature of $25^{\circ} \mathrm{C}$ are shown in Fig. 7. The correlation coefficients indicate that adsorption was fitted better by the Langmuir $\left(R^{2}=0.993-0.999\right)$ than the Freundlich model $\left(R^{2}=0.947-0.992\right)$, as shown in Fig. 7. Therefore, the adsorption process can be described by the formation of monolayer coverage of the adsorbate on the adsorbents surface. Maximum adsorption capacity, $q_{\mathrm{m}}$ (mg/g), was found to be $522.8 \mathrm{mg} / \mathrm{g}$ for $\mathrm{Zn}-\mathrm{OCMK}-3$. Values of adsorption capacity of the other adsorbents are given in Table 5 for comparison.
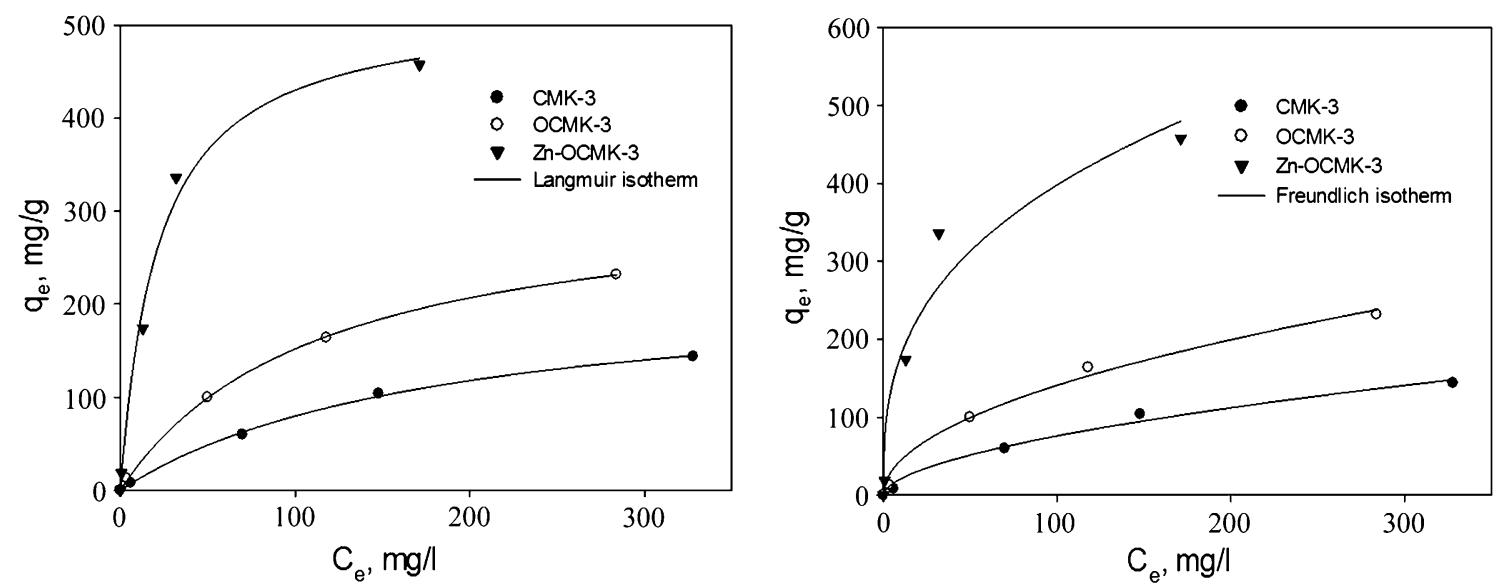

Fig. 7 Freundlich (left) and Langmuir (right) isotherms for Pb(II) adsorption onto synthesized mesoporous carbons: CMK-3, OCMK-3, and ZnOCMK-3 
Table 5 The equilibrium capacities of $\mathrm{Pb}$ (II) on various adsorbents

\begin{tabular}{llll}
\hline Adsorbent & $q_{\mathrm{m}}(\mathrm{mg} / \mathrm{g})$ & $\mathrm{pH}$ & Reference \\
\hline Mn oxide-coated carbon nanotubes & 78.74 & 7 & Wang et al. (2007) \\
Bentonite & 52.63 & 3.4 & Naseem and Tahir (2001) \\
Granular activated carbon & 29.44 & 5 & Goel et al. (2005) \\
Sea nodule residues & 107.52 & 5.5 & Agrawal et al. (2005) \\
\hline
\end{tabular}

\section{Effect of $\mathrm{HNO}_{3}$ treatment and $\mathrm{ZnO}$ coating}

The texture and surface chemistry of synthesized mesoporous carbon were modified by means of $\mathrm{HNO}_{3}$ treatment in liquid phase to optimize their ability of dispersing active $\mathrm{ZnO}$ particles. As it can be seen from Table 6, the maximum adsorption capacity, $q_{\mathrm{m}}$, of $522.8 \mathrm{mg} / \mathrm{g}$ $(2.52 \mathrm{mmol} / \mathrm{g})$ for $\mathrm{Zn}-\mathrm{OCMK}-3$ is the largest among the adsorbents for the $\mathrm{Pb}(\mathrm{II})$ adsorption, and it is close to the amounts of zinc oxide-coated $(2.38 \mathrm{mmol} / \mathrm{g})$ ("Amount of $\mathrm{ZnO}$ coating"), suggesting the monolayer spreading of zinc oxide onto the OCMK-3 surface, while $323.1 \mathrm{mg} / \mathrm{g}$ ( $1.56 \mathrm{mmol} / \mathrm{g}$ ) of $q_{\mathrm{m}}$ for OCMK-3 is limited to only $52 \%$ of the carboxylic sites of 3.00 meq./g, and $225.1 \mathrm{mg} / \mathrm{g}$ $(1.08 \mathrm{mmol} / \mathrm{g})$ of $q_{\mathrm{m}}$ for CMK-3 is limited to $67.5 \%$ of the phenolic sites of 1.60 meq./g determined by the Boehm titration ("Characterization of adsorbents"). The results suggest that zinc oxide-coated OCMK-3 can be effectively used for $\mathrm{Pb}$ (II) adsorption, whereas a part of acidic functional groups, probably those on the external surface, will contribute to binding the $\mathrm{Pb}(\mathrm{II})$ for the OCMK-3 and CMK-3.

Table 6 Kinetic adsorption parameters obtained using pseudo-first-order and pseudo-second-order models for the removal of $\mathrm{Pb}$ (II) by $\mathrm{CMK}-3$, OCMK-3 and Zn-OCMK-3

\begin{tabular}{|c|c|c|c|c|c|c|}
\hline Adsorbents & Kinetic models & $\mathrm{Pb}$ concentration & $k^{\mathrm{a}}$ & $q_{\mathrm{e}, \mathrm{cal}}(\mathrm{mg} / \mathrm{g})$ & $q_{\mathrm{e}, \exp }(\mathrm{mg} / \mathrm{g})$ & $R^{2}$ \\
\hline \multirow[t]{8}{*}{ CMK-3 } & \multirow[t]{4}{*}{ Pseudo-first-order } & 10 & 0.043 & 2.51 & 8.00 & 0.986 \\
\hline & & 100 & 0.050 & 40.13 & 60.00 & 0.995 \\
\hline & & 200 & 0.030 & 85.86 & 104.00 & 0.875 \\
\hline & & 400 & 0.028 & 93.95 & 144.00 & 0.954 \\
\hline & \multirow[t]{4}{*}{ Pseudo-second-order } & 10 & 0.036 & 8.26 & 8.00 & 0.999 \\
\hline & & 100 & 0.001 & 71.42 & 60.00 & 0.999 \\
\hline & & 200 & 0.0007 & 111.11 & 104.00 & 0.989 \\
\hline & & 400 & 0.0005 & 166.66 & 144.00 & 0.972 \\
\hline \multirow[t]{8}{*}{ OCMK-3 } & \multirow[t]{4}{*}{ Pseudo-first-order } & 10 & 0.037 & 4.26 & 13.00 & 0.903 \\
\hline & & 100 & 0.035 & 70.29 & 100.00 & 0.982 \\
\hline & & 200 & 0.026 & 102.81 & 164.00 & 0.950 \\
\hline & & 400 & 0.019 & 137.42 & 232.00 & 0.942 \\
\hline & \multirow[t]{4}{*}{ Pseudo-second-order } & 10 & 0.020 & 13.33 & 13.00 & 0.994 \\
\hline & & 100 & 0.0007 & 111.11 & 100.00 & 0.988 \\
\hline & & 200 & 0.0006 & 166.66 & 164.00 & 0.970 \\
\hline & & 400 & 0.0004 & 250.00 & 232.00 & 0.968 \\
\hline \multirow[t]{8}{*}{ Zn-OCMK-3 } & \multirow[t]{4}{*}{ Pseudo-first-order } & 10 & 0.036 & 5.56 & 18.60 & 0.907 \\
\hline & & 100 & 0.023 & 86.56 & 174.24 & 0.949 \\
\hline & & 200 & 0.024 & 144.62 & 336.00 & 0.959 \\
\hline & & 400 & 0.027 & 182.96 & 457.60 & 0.980 \\
\hline & \multirow[t]{4}{*}{ Pseudo-second-order } & 10 & 0.016 & 18.86 & 18.60 & 0.995 \\
\hline & & 100 & 0.0005 & 200.00 & 174.24 & 0.984 \\
\hline & & 200 & 0.0004 & 333.33 & 336.00 & 0.984 \\
\hline & & 400 & 0.0003 & 500.00 & 457.60 & 0.995 \\
\hline
\end{tabular}

\footnotetext{
${ }^{a} k$ for pseudo-first-order model is $k_{1}(\mathrm{~L} / \mathrm{min})$ and for pseudo-second-order model is $k_{2}(\mathrm{~g} / \mathrm{mg} \min )$
} 
The Langmuir isotherm model shows that the $b$ value of $\mathrm{Pb}$ (II) onto $\mathrm{Zn}-\mathrm{OCMK}-3(0.0465 \mathrm{~L} / \mathrm{mg})$ is higher than those of OCMK-3 (0.0089 L/mg) and CMK-3 (0.0055 L/mg), indicating that the adsorption affinity for $\mathrm{Zn}-\mathrm{OCMK}-3$ is higher compared to OCMK-3 and CMK-3.

Furthermore, the ability of Freundlich model to fit the experimental data was examined. For this case, the plot of $q_{\mathrm{e}}$ versus $C_{\mathrm{e}}$ was employed to generate the slop value of $K_{\mathrm{f}}$ and the magnitude of $1 / n$. The Freundlich constant, $K_{\mathrm{f}}$, which is related to the adsorption capacity of the adsorbent, was found to be 5.73, 14.04, and $80.08(\mathrm{mg} / \mathrm{g})(\mathrm{L} / \mathrm{mg})^{1 / n}$ for CMK-3, OCMK-3, and Zn-OCMK-3, respectively. These values showed a trend similar to that of the Langmuir constant, $q_{\mathrm{m}}$. The magnitude of $n$ represents the measure of both the relative magnitude and diversity of energies associated with $\mathrm{Pb}(\mathrm{II})$ adsorption onto adsorbents. The values of $n$ are all $>1$ (1.78 for CMK-3, 2.00 for OCMK-3, and 2.87 for Zn-OCMK-3), indicative of high adsorption intensity (Benhamou et al. 2009). On the other hand, the adsorption affinity and adsorption intensity increased as follows, Zn-OCMK-3 > OCMK-3 > CMK-3, with similar increase in the $n$ and $b$ values in the Freundlich and Langmuir isotherm models.

The mesoporous carbon thanks to its developed porous structure and high specific surface area which can accommodate zinc oxide in a spreading manner, probably the zinc connects to the mesoporous carbon surface via oxygen atoms, for the adsorptive removal of heavy metals. From FT-IR spectra in "Properties of adsorbents" and Table 1, it can be seen that the oxidation with nitric acid can increase the carboxylic groups more than other functional groups on the mesoporous carbon surface. Thus, it can be deduced that the carboxylic functional groups are mostly responsible for binding heavy metal ions on OCMK-3. Tamura and Furuichi (1997) examined the adsorption of heavy metals onto $\mathrm{MnO}_{2}$ and $\mathrm{Fe}_{2} \mathrm{O}_{3}$, and concluded that surface hydroxyl groups contributed to the binding of heavy metals for the metal oxide. In fact, a covalent bond is formed between hydroxyl groups on $\mathrm{ZnO}$ and $\mathrm{Pb}(\mathrm{II})$. Also, the $\mathrm{ZnO}$ can bond with heavy metal ions by coordination bonds (Fig. 8).

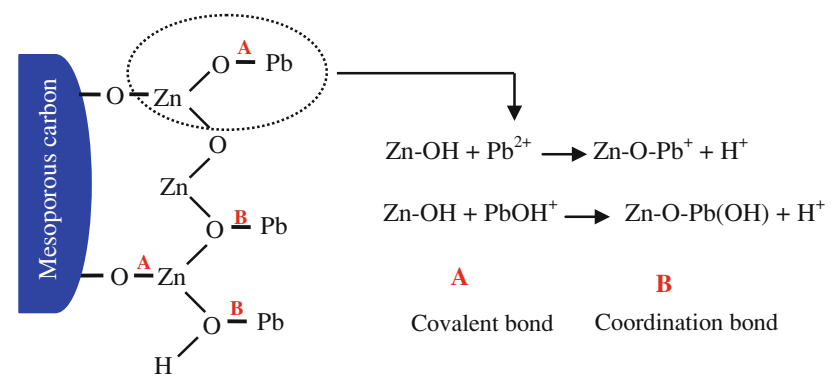

Fig. 8 Diagram of the formation of $\mathrm{ZnO}$ onto mesoporous carbon and $\mathrm{ZnO}$ binding with $\mathrm{Pb}$ ions
Adsorption kinetics of $\mathrm{Pb}(\mathrm{II})$

The study of adsorption kinetics is significant as it provides valuable insights into the reaction pathways and the mechanism of the reactions. Any adsorption process is normally controlled by the three diffusion steps: (1) transport of the solute from bulk solution to the film surrounding the adsorbent, (2) from the film to the adsorbent surface, and (3) from the surface to the internal sites followed by binding of the metal ions to the active sites. The slowest steps determine the overall rate of the adsorption process and usually it is thought that the step (2) leads to surface adsorption and the step (3) leads to intra-particle adsorption. Several kinetic models are used to explain the mechanism of the adsorption processes. A simple pseudofirst-order equation is given by Lagergren equation (Eq. 12) (Sharma and Bhattacharyya 2004):

$\ln \left(q_{\mathrm{e}}-q_{t}\right)=\ln q_{\mathrm{e}}-k_{1} t$

where $q_{\mathrm{e}}$ and $q_{t}$ are the amounts of $\mathrm{Pb}(\mathrm{II})$ adsorbed $(\mathrm{mg} / \mathrm{g}$ ) at equilibrium time and any time $t$, respectively, and $k_{1}$ is the rate constant of pseudo-first-order adsorption process (L/min). Plot of $\ln \left(q_{\mathrm{e}}-q_{t}\right)$ versus $t$ gives a straight line for first pseudo-first-order adsorption kinetic which allows computation of the rate constant of pseudo-first-order adsorption process $\left(k_{1}\right)$ (Fig. 9). The calculated $q_{\mathrm{e}}, k_{1}$ and the corresponding linear regression correlation coefficient $\left(R^{2}\right)$ values are presented in Table 6. As seen from this table, the experimental $q_{\mathrm{e}}$ values did not agree with the calculated values obtained from the linear plots. The pseudo-second-order kinetic equation (Eq. 13) based on equilibrium adsorption is expressed as (Benguell and Benaissa 2002):

$\frac{t}{q_{t}}=\frac{1}{k_{2} q_{\mathrm{e}}^{2}}+\frac{1}{q_{\mathrm{e}}} t$

where $k_{2}$ is the rate constant of pseudo-second-order adsorption process $(\mathrm{g} / \mathrm{mg} \mathrm{min}), q_{\mathrm{e}}$ and $q_{t}$ represent the amount of $\mathrm{Pb}$ (II) adsorbed at equilibrium and at any time (mg/g). Linear plots of $t / q_{t}$ versus $t$ are shown in Fig. 9. Furthermore, the calculated $q_{\mathrm{e}}, k_{2}$ and the corresponding linear regression correlation coefficient $\left(R^{2}\right)$ values are given in Table 6. As seen from Table 6, the values of $q_{\mathrm{e}}$ calculated from pseudo-second-order adsorption kinetic almost agreed well with the experimental values of $q_{\mathrm{e}}$. From the $R^{2}$ and the calculated $q_{e}$, it was found that the adsorption of $\mathrm{Pb}$ (II) on the prepared mesoporous carbons follows pseudo-second-order adsorption kinetic. When the initial $\mathrm{Pb}$ (II) ion concentration was increased from 10 to $400 \mathrm{mg} / \mathrm{L}$, the pseudo-second-order rate constant diminished from 0.016 to $0.0003 \mathrm{~g} / \mathrm{mg} \mathrm{min}$ for $\mathrm{Zn}-\mathrm{OCMK}-3$, from 0.020 to $0.0004 \mathrm{~g} / \mathrm{mg}$ min for OCMK-3, and from 0.036 to $0.0005 \mathrm{~g} / \mathrm{mg}$ min for CMK-3 as shown in Table 6 . 
Fig. 9 Linearization of $\mathrm{Pb}(\mathrm{II})$ adsorption kinetic (pseudo-firstorder rate (left figures) and pseudo-second-order rate (right figures)] onto CMK-3 (a, b), OCMK-3 (c, d), and Zn-OCMK-3 (e, f)
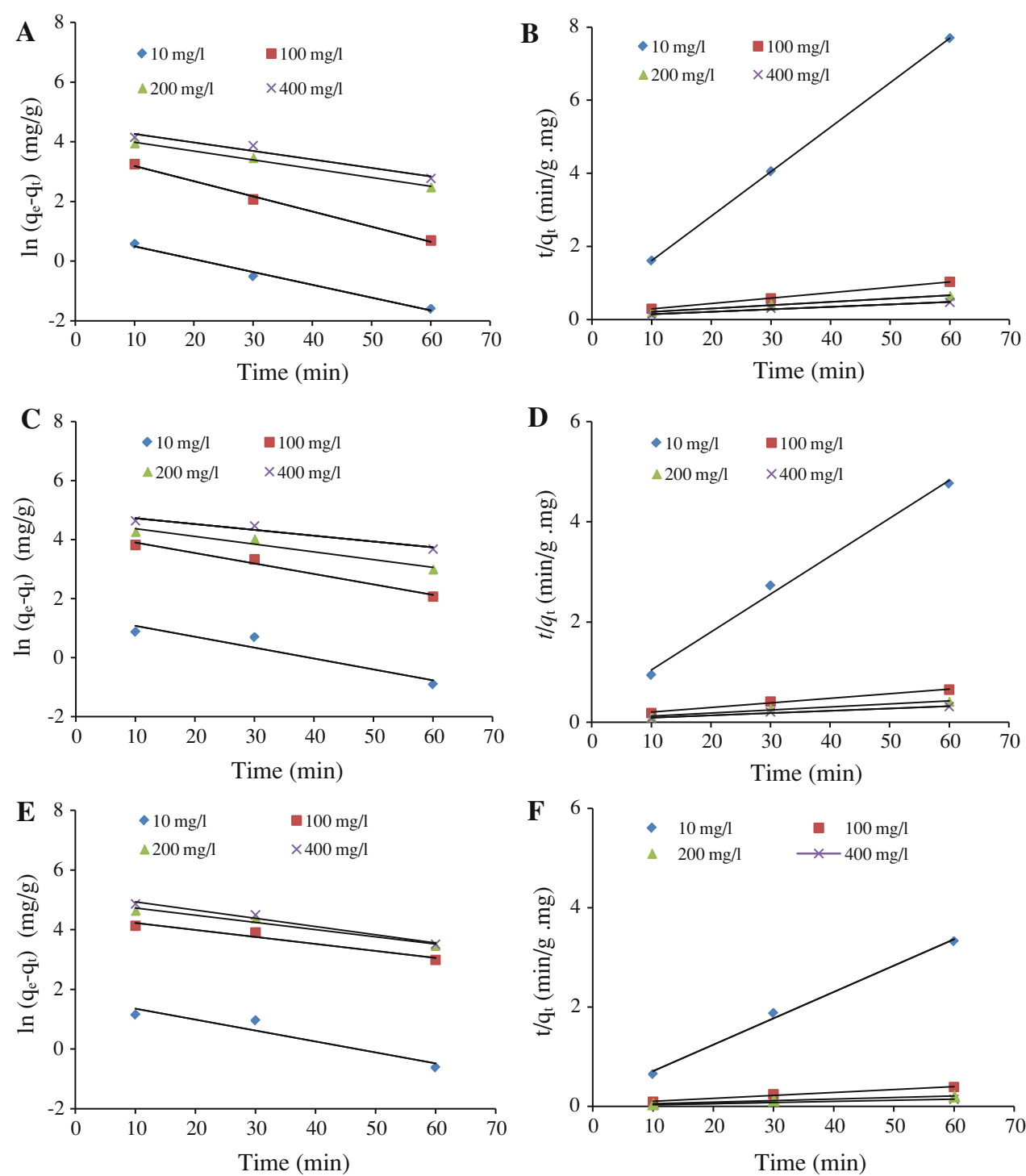

It means that the value of $k_{2}$ depended on the $C_{0}$ and the rate constant of pseudo-second-order adsorption process decreased as the initial $\mathrm{Pb}$ (II) ion concentration was increased. The results from Table 6 confirmed this claim. Similar results have been observed for $\mathrm{Pb}$ (II) adsorption (Hamadi et al. 2001; Ho et al. 2001).

\section{Regeneration of Zn-OCMK-3}

Regeneration studies help the recovery of the metal ions from wastewater and the recycling of adsorbent (Saeed and Iqbal 2003). The regeneration of adsorbent is one of the important factors which affect the overall cost of the adsorption process. Regeneration of $\mathrm{Pb}(\mathrm{II})$ using $\mathrm{HCl}$ solution by disruption of coordination of $\mathrm{Pb}$ (II) with the surface of $\mathrm{Zn}$-OCMK-3 and subsequent release into desorption medium was studied. The results showed that with increase in concentration of $\mathrm{HCl}$ solution the desorption also increased, but attained constant at $0.2 \mathrm{M}$ $\mathrm{HCl}$ for $\mathrm{Pb}$ (II) (Fig. 10a). The Zn-OCMK-3 was reused in three successive adsorption-desorption cycles. Figure 10b shows regenerated use of Zn-OCMK-3 adsorbent for removal of $\mathrm{Pb}(\mathrm{II})$. The adsorption-desorption studies of the $\mathrm{Zn}$-OCMK-3 indicated a loss in the adsorption capacity of $4.84 \%$ after first cycle, $7.27 \%$ after second cycle and $8.99 \%$ after third cycle compared to the initial cycle, indicating a good regeneration capacity of the adsorbent.

\section{Conclusion}

Based on the experimental results for Zn-OCMK-3, the following conclusions can be deduced: 

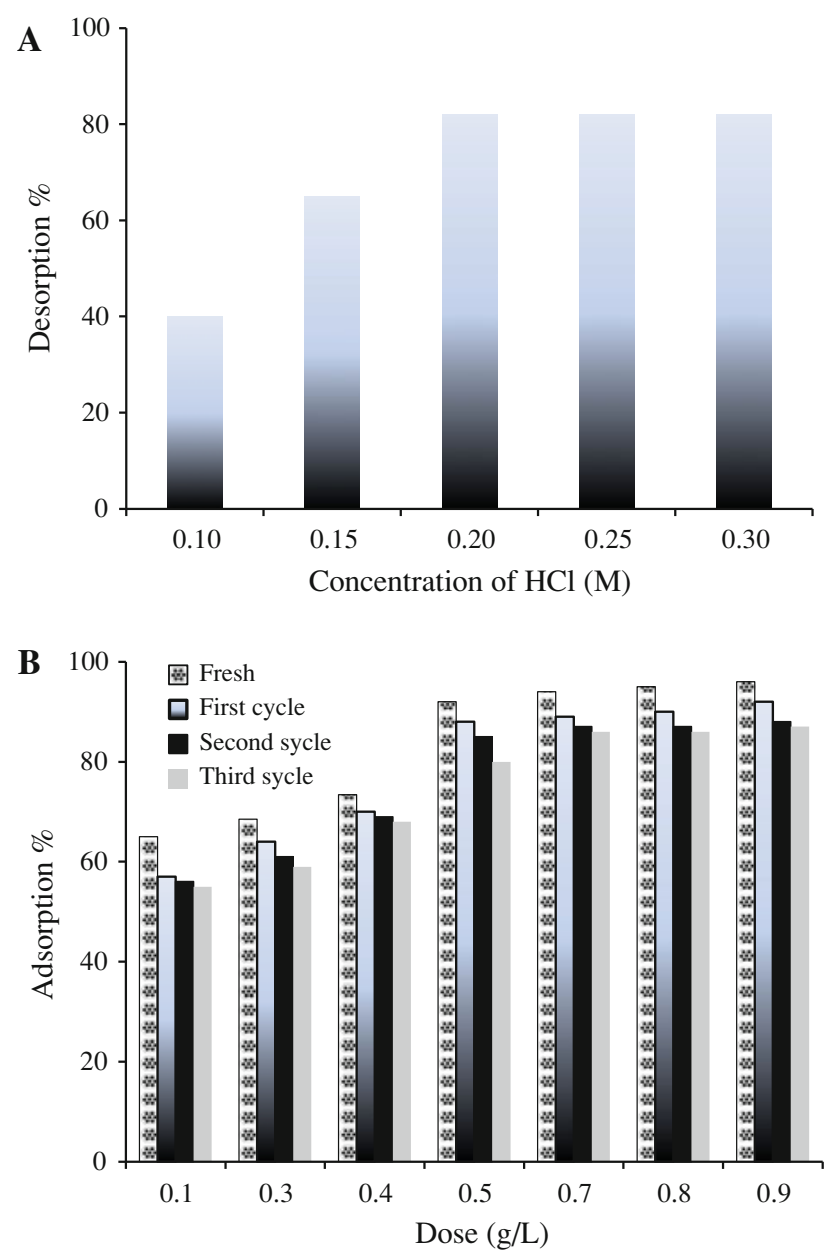

Fig. 10 Reversibility of adsorption. a Effect of $\mathrm{HCl}$ concentration on the desorption of $\mathrm{Pb}$ (II) from the $\mathrm{Zn}$-OCMK-3. b Regenerated use of $\mathrm{Zn}$-OCMK-3 adsorbent for removal of $\mathrm{Pb}(\mathrm{pH}=6$, agitation time $=$ $120 \mathrm{~min}$, agitation speed $=150 \mathrm{rpm}, \quad$ temperature $=25 \pm 1{ }^{\circ} \mathrm{C}$, concentration of $\mathrm{HCl}=0.20 \mathrm{M}$ )

1. $\mathrm{ZnO}$ prepared on ordered mesoporous carbon has shown a good performance for removal of $\mathrm{Pb}$ (II) from aqueous solution. The amount of $\mathrm{ZnO}$ coated onto the OCMK-3 as a function of the number of $\mathrm{ZnO}$ loading cycles was studied. It was observed that $\mathrm{Zn}$ (II) increased with increase in the number of cycles. It can be concluded that during the first cycle, the zinc coating will also principally take place, binding with acidic functional groups on the mesoporous carbon followed by binding with the rest of them and via zinc oxide from the second through fourth steps.

2. The optimum conditions for removal of $\mathrm{Pb}$ (II) were as follows: (1) The agitation time was $120 \mathrm{~min}$; (2) the initial concentration was $10 \mathrm{mg} / \mathrm{L}$; (3) the temperature was $35^{\circ} \mathrm{C}$; (4) the dose was $0.7 \mathrm{~g} / \mathrm{L}$; and (5) the $\mathrm{pH}$ was 6 . In this study, some other test conditions were predicted. The overall experimental error was $1.75 \%$, this estimating is acceptable.
3. The isotherm fitted well into the Langmuir model and kinetics data were best fitted to the pseudo-secondorder model. Zn-OCMK-3 can be used to detoxify water, wastewaters and effluents containing $\mathrm{Pb}$ (II) with favorable adsorption kinetics and maximum adsorption capacity of $522.8 \mathrm{mg} / \mathrm{g}$. Most of the zinc oxide-coated to the OCMK-3 can be effectively used for the $\mathrm{Pb}$ (II) adsorption compared with the CMK-3 and OCMK-3, because the number of $\mathrm{Pb}$ (II) adsorption sites calculated from the isotherms was close to the measured number of zinc oxide-coated, but they were far less than the number of carboxyl groups introduced by the oxidation of mesoporous carbon and hydroxyl groups on the CMK-3.

4. Although a slight decrease in adsorption capacity was observed in subsequent cycles, it can be concluded that Zn-OCMK-3 is appropriate for practical applications for the remediation of $\mathrm{Pb}(\mathrm{II})$ from polluted water.

Acknowledgments We appreciate Dr. Mehdi Nasiri because of his close guidance. The authors also thank Iran University of Science and Technology for considerable laboratory support at the Research Laboratory of Nanoporous Materials, Iran Nanotechnology Initiative Council, and Tarbiat Modares University.

\section{References}

Agrawal A, Sahu KK, Pandey BD (2005) Systematic studies on adsorption of lead on sea nodule residues. J Colloid Interface Sci 281:291-298

Anbia M, Mohammadi K (2008) Removal of copper-phthalocyanine from aqueous solution by cationically templated MCM-41 and MCM-48 nanoporous adsorbents. Chin J Chem 26:2051-2055

Anbia M, Mohammadi N (2009) A nanoporous adsorbent for removal of furfural from aqueous solutions. Desalination 249:150-153

Anbia M, Moradi SE (2009) Removal of naphthalene from petrochemical wastewater streams using carbon nanoporous adsorbent. Appl Surf Sci 255:5041-5047

Anbia M, Mohammadi N, Mohammadi K (2010) Fast and efficient mesoporous adsorbents for the separation of toxic compounds from aqueous media. J Hazard Mater 176:965-972

Atil H, Unver Y (2000) A different approach of experimental design: Taguchi method. Pak J Biol Sci 3:1538-1540

Ayranci E, Hoda N (2005) Adsorption kinetics and isotherms of pesticides onto activated carbon-cloth. Chemosphere 60:16001607

Baniamerian MJ, Moradi SE, Noori A, Salahi H (2009) The effect of surface modification on heavy metal ion removal from water by carbon nanoporous adsorbent. Appl Surf Sci 256:1347-1354

Bazula PA, Lu AH, Nitz JJ, Schuth F (2008) Surface and pore structure modification of ordered mesoporous carbons via a chemical oxidation approach. Microporous Mesoporous Mater. 108:266-275

Benguell B, Benaissa H (2002) Cadmium removal from aqueous solutions by chitin: kinetic and equilibrium studies. Water Res 36:2463-2474

Benhamou A, Baudu M, Derriche Z, Basly JP (2009) Aqueous heavy metals removal on amine functionalized Si-MCM-41 and Si-MCM48. J Hazard Mater 171:1001-1008 
Boehm HP (2002) Surface oxides on carbon and their analysis: a critical assessment. Carbon 40:145-149

Chen X, Jeyaseelan S, Graham N (2002) Physical and chemical properties study of the activated carbon made from sewage sludge. Waste Manag 22:755-760

Colilla M, Balas F, Manzano M, Vallet-Regi M (2008) Novel method to synthesize ordered mesoporous silica with high surface areas. Solid State Sci 10:408-415

Eiden CA, Jewell CA, Wightman JP (1980) Interaction of lead and chromium with chitin and chitosan. J Appl Polym Sci 25:15871599

El-demerdash FM, Elegamy EI (1996) Biological effects in Tilapia nilotica fish as indicators of pollution by cadmium and mercury. Int J Environ Healthy Res 9:173-186

Emmett PH (1954) Measurements of the surface area of solid catalysts, in cataysis. Reinhold Publishing Corporation, New York

Goel J, Kadirvelu K, Rajagopal C, Garg VK (2005) Removal of lead(II) by adsorption using treated granular activated carbon: batch and column studies. J Hazard Mater 125:211-220

Gregg SJ, Sing KSW (1982) Adsorption, surface area and porosity. Academic Press, London

Hamadi NK, Chen XD, Farid MM, Lu MGQ (2001) Adsorption kinetics for the removal of chromium(VI) from aqueous solution by adsorbents derived from used tyres and sawdust. Chem Eng $\mathrm{J}$ 84:95-105

Han RP, Zou WH, Zhang ZP, Shi J, Yang JJ (2006) Removal of copper(II) and lead(II) from aqueous solution by manganese oxide coated sand I. Characterization and kinetic study. J Hazard Mater 137:384-395

Heidari A, Younesi H, Mehraban Z (2009) Removal of Ni(II), Cd(II), and $\mathrm{Pb}(\mathrm{II})$ from a ternary aqueous solution by amino functionalized mesoporous and nanomesoporous silica. Chem Eng J 153(1-3):70-79

Ho YS, Ng JCY, McKay G (2001) Removal of lead(II) from effluents by sorption on peat using second-order kinetics. Sep Sci Technol 36:241-261

Ho Y, Porter J, McKay G (2002) Equilibrium isotherm studies for the sorption of divalent metal ions onto peat: copper, nickel and lead single component systems. Water Air Soil Pollut 141:1-33

Jun S, Joo SH, Ryoo R, Kruk M, Jaroniec M, Liu Z, Ohsuna T, Terasaki O (2000) Synthesis of new, nanoporous carbon with hexagonally ordered mesostructure. J Am Chem Soc 122:10712 10713

Karagoz S, Tay T, Ucar S (2008) Activated carbon from waste biomass by sulphuric acid activation and their use on methylene blue adsorption. Biores Technol 99:6214-6222

Kikuchi Y, Qian Q, Machida M, Tatsumoto H (2006) Effect of ZnO loading to activated carbon on $\mathrm{Pb}(\mathrm{II})$ adsorption from aqueous solution. Carbon 44:195-202

Kresge CT, Leonowicz ME, Roth WJ, Vartuli JC, Beck JS (1992) Ordered mesoporous molecular sieves synthesized by a liquidcrystal template mechanism. Nature 359:710-712

Kruk M, Jaroniec M (2001) Gas adsorption characterization of ordered organic-inorganic nanocomposite materials. Chem Mater 13: 3169-3183

Li YH, Wang SG, Wei JQ, Zhang XF, Xu CL, Luan ZK, Wu DH, Wei BQ (2002) Lead adsorption on carbon nanotubes. Chem Phys Lett 357:263-266

Li YH, Di ZC, Ding J, Wu DH, Luan ZK, Zhu YQ (2005) Adsorption thermodynamic, kinetic and desorption studies of $\mathrm{Pb}^{2+}$ on carbon nanotubes. Water Res 39:605-609

Malakootian M, Nouri J, Hossaini H (2009) Removal of heavy metals from paint industry's wastewater using Leca as an available adsorbent. Int J Environ Sci Technol 6(2):183-190
Mangrulkar PA, Kamble SP, Meshram J, Rayalu SS (2008) Adsorption of phenol and o-chlorophenol by mesoporous MCM-41. J Hazard Mater 160:414-421

Marzal P, Seco A, Gabaldo C, Ferrer J (1996) Cadmium and zinc adsorption onto activated carbon: influence of temperature, $\mathrm{pH}$ and metal/carbon ratio. J Chem Technol Biotechnol 66:279-285

Morey MS, O'Brien S, Schwarz S, Stucky GD (2000) Hydrothermal and postsynthesis surface modification of cubic, MCM-48, and ultralarge pore SBA-15 mesoporous silica with titanium. Chem Mater 12:898-911

Naseem R, Tahir SS (2001) Removal of Pb(II) from aqueous/acidic solutions by using bentonite as an adsorbent. Water Res 35(16): 3982

Noll KE, Gounaris V, Hou WS (1992) Adsorption technology for air and water pollution control. Lewis Publisher, Michigan

Purna Chandra Rao G, Satyaveni S, Ramesh A, Seshaiah K, Murthy KSN, Choudary NV (2006) Sorption of cadmium and zinc from aqueous solutions by zeolite $4 \mathrm{~A}$, zeolite $13 \mathrm{X}$ and bentonite. J Environ Manag 81:265-272

Ryoo R, Joo SH, Jun S (1999) Synthesis of highly ordered carbon molecular sieves via template-mediated structural transformation. J Phys Chem B 103:7743-7746

Ryoo R, Joo SH, Kruk M, Jaroniec M (2001) Ordered mesoporous carbons. Adv Mater 13(9):677-681

Saeed A, Iqbal M (2003) Bioremoval of cadmium from aqueous solution by black gram husk (Cicerarientinum). Water Res 37:3472-3480

Seco A, Marzal P, Gabaldo C (1997) Adsorption of heavy metals from aqueous solutions onto activated carbon in single $\mathrm{Cu}$ and $\mathrm{Ni}$ systems and in binary $\mathrm{Cu} . \mathrm{Ni}, \mathrm{Cu} . \mathrm{Cd}$ and $\mathrm{Cu} . \mathrm{Z}$ systems. J Chem Technol Biotechnol 68:23-30

Shahbazi A, Younesi H, Badiei A (2011) Functionalized SBA-15 mesoporous silica by melamine-based dendrimer amines for adsorptive characteristics of $\mathrm{Pb}(\mathrm{II}), \mathrm{Cu}(\mathrm{II})$ and $\mathrm{Cd}(\mathrm{II})$ heavy metal ions in batch and fixed bed. Chem Eng J 168(2):505-518

Sharma A, Bhattacharyya KG (2004) Adsorption of chromium(VI) on Azadirachta Indica (Neem) leaf powder. Adsorption 10: 327-338

Smiciklas ID, Milonjic SK, Pfendt P, Raicevic S (2000) The point of zero charge and sorption of cadmium (II) and strontium (II) ions on synthetic hydroxyapatite. Sep Purif Technol 18:185-194

Stevenson FJ (1994) Humus chemistry: genesis, composition, reactions, 2nd edn. John Wiley and Sons, New York

Taguchi G (1990) Introduction to quality engineering. McGraw-Hill, New York

Taguchi A, Schuth F (2005) Ordered mesoporous materials in catalysis. Microporous Mesoporous Mater. 77:1-45

Tamura H, Furuichi R (1997) Adsorption affinity of divalent heavy metal ions for metal oxides evaluated by modeling with the Frumkin isotherm. J Colloid Interface Sci 195:241-249

Urik M, Littera P, Sevc J, Kolencik M, Cernansky S (2009) Removal of arsenic (V) from aqueous solutions using chemically modified sawdust of spruce (Picea abies): kinetics and isotherm studies. Int J Environ Sci Tech 6(3):451-456

Vinke P, Eijk MV, Verbree M, Voskamp AF, Bekkum HV (1994) Modification of the surfaces of a gas activated carbon and a chemically activated carbon with nitric acid, hypochlorite, and ammonia. Carbon 32:675-686

Vinu A, Hossian KZ, Srinivasu P, Miyahara M, Anandan S, Gokulakrishnan N, Mori T, Ariga K, Balasubramanian VV (2007) Carboxy-mesoporous carbon and its excellent adsorption capability for proteins. J Mater Chem 17:1819-1825

Vukojevic Medvidovic N, Peric J, Trgo M (2006) Column performance in lead removal from aqueous solutions by fixed bed of natural zeolite-clinoptilolite. Sep Purif Technol 49:237-244 
Wagner A, Boman J (2003) Biomonitoring of trace elements in muscle and liver tissue of freshwater fish. Spectrochimica Acta Part B. 58:2215-2226

Wang SG, Gong WX, Liu XW, Yao YW, Gao BY, Yue QY (2007) Removal of lead(II) from aqueous solution by adsorption onto manganese oxide-coated carbon nanotubes. Sep Purif Technol 58:17-23

Xu Y, Xie Z, Xue L (2011) Chelation of heavy metals by potassium butyl dithiophosphate. J. Environ Sci 23(5):778-783

Zhao D, Feng J, Huo Q, Melosh N, Fredrickson GH, Chmelka BF, Stucky GD (1998a) Triblock copolymer syntheses of mesoporous silica with periodic 50 to 300 angstrom pores. Science 279: $548-552$
Zhao D, Huo Q, Feng J, Chmelka BF, Stucky GD (1998b) Nonionic triblock and star diblock copolymer and oligomeric surfactant syntheses of highly ordered, hydrothermally stable, mesoporous silica structures. J Am Chem Soc 120:6024-6036

Zolfaghari G, Esmaili-sari A, Ghasempouri SM, HassanzadeKiabi B (2007) Examination of mercury concentration in the feather of 18 species of birds in southwest Iran. Environ Res 104:258-265 